\title{
Diagnosing Melancholia in the Victorian Asylum
}

A typical case of melancholia, as we shall see, runs a somewhat definite course, like a fever, and has often all the characters of an acute disease, in this being to the physician unlike a mere feeling of melancholy. ${ }^{1}$

Thomas S. Clouston (1883)

On 15 August 1874, a young doctor was admitted as a private patient into the Royal Edinburgh Asylum at Morningside. On the medical certificate and reception order that accompanied his arrival it was stated that the patient, Moses B., was 'suicidal'. The two certifying physicians testified that the patient had communicated to them a belief that his soul was lost. He was reported as having taken 'a poisonous dose of Belladonna', and his father and brother had seen it necessary to have him sent to the asylum since they felt that he could not 'be left alone' for the fear 'that he would seek to destroy himself'. Upon admission, the attending physician determined that his 'depression' was 'considerable', and made a note of his 'suicidal tendencies', which consisted in 'taking belladonna, refusing food, \&c'. The patient's recent mental symptoms were listed as 'delusions such as that his soul is lost, that he ought to die, and thinks he is committing great sins'. He was given the diagnosis melancholia, with a special reference made to his persistent suicidal tendencies. ${ }^{2}$

Å Jansson, From Melancholia to Depression, Mental Health in Historical Perspective, https://doi.org/10.1007/978-3-030-54802-5_6 
Moses was what today might be referred to as a 'textbook case' of melancholia in the late-Victorian period: profound depression of mind, delusions of a religious nature, and persistent suicidal tendencies. Once inside the walls of Morningside, his case notes tell of repeated attempts by the patient to take his own life. Moses was considered such an exemplary case of melancholia that Joseph Brown, assisting physician at the asylum, proceeded to write up the case as an article for the Edinburgh Medical Journal later that year, presented as a typical case of 'suicidal melancholia' that served as a 'striking illustration of the great difficulty there exists in preventing a determined suicidal patient from accomplishing his object'. ${ }^{3}$ According to Morningside's superintendent, Thomas Clouston, such cases were becoming increasingly common. In his annual report submitted that same year to the Board of Commissioners, the body overseeing the management of Scottish asylums, Clouston remarked that in 1874 ,

[t]he number whose malady was characterised by depression of mind was most unusually large. I find no fewer than 88 under the head of Melancholia, a number greater by 70 per cent than the average number classified under that heading during the previous ten years, though, as we have seen, the excess of admissions this year was only 14 per cent. Many of the worst of these cases were more desperately intent on taking away their own lives than any patients I have ever had. The ingenuity, determination, and persistence of this suicidal propensity in some of them would scarcely be believed by any one who had not experienced it. ${ }^{4}$

The statistical tables accompanying the report confirmed Clouston's assessment: of the 88 melancholic patients admitted, 67 were listed as exhibiting 'suicidal tendencies'. It certainly appeared that an unusually large number of people suffered from melancholia in 1874, and that a significant majority were intent on taking their own lives. However, like many of his peers Clouston suggested that statistical tables did not necessarily represent a simple, discoverable truth. The Union of Chargeability $\mathrm{Act}^{5}$ passed in the previous decade had made pauper lunatics in England and Wales chargeable to unions instead of single parishes, resulting in a rise in admissions of pauper patients in English asylums. This, Clouston argued, had been held up by a number of people 'as proof that lunacy was rapidly on the increase' across the border in the south, but in fact it 'merely shewed how the numbers of the registered insane were increased by an Act of Parliament'. 6 
When deploying Clouston's own reasoning to the statistics on melancholia, a similar picture could be seen to emerge. The increase in melancholic patients coincided with Clouston's appointment as superintendent of Morningside the previous year following the death of his predecessor, David Skae. This event produced a shift in the type of diagnostic categories used in the hospital, as Clouston replaced the existing, somewhat eclectic, system based on Skae's aetiological classification with a more uniform and standardised one. Following Clouston's own logic, then, the statistical increase in patients diagnosed with melancholia was at least in part the result of different diagnostic practices. While key symptoms were often initially noted on the patient's medical certificate, a formal diagnosis was assigned by an asylum physician once the patient had been admitted. To recap briefly from Chapter 5 , when a person was to be admitted into the asylum they would first be examined by two physicians $^{7}$ who would each sign a medical certificate including descriptions of the 'facts indicating insanity' in the person to be certified. This would include any 'symptoms', such as 'mental depression', 'excitement', 'incoherence', 'delusions', 'poor memory', and so on. Accompanying the medical certificates would be a reception order signed by whoever was having the patient committed-usually a relative, friend, guardian, or poorhouse official. This person would have to note on the form whether the suspected lunatic was 'epileptic', 'suicidal', or 'dangerous to others'. When the patient arrived in the asylum, the information about their state of mind would be transferred to the casebook, and added to this would be various details about the lunatic's mental and physical state upon admission. Finally, within a few days, a diagnosis would be entered based upon the information given.

These acts had to take place before a person was counted as 'melancholic' in asylum statistics, and in this process various phenomena were observed in light of those already noted. A noteworthy feature of the vast number of melancholics admitted into Morningside during Clouston's reign was the widely diverse range of human activities and expressions that were merged under the melancholia banner and read as signs of mental depression and suicidality. This is particularly striking when one considers that during the period considered here-from the mid-1870s until the turn of the twentieth century-melancholia was in published material, including the several editions of Clouston's textbook, described in remarkably standardised language with a relatively homogenous range of symptoms. As melancholia was solidified as an independent diagnosis 
with a precise symptom picture in the last quarter of the century, the contrast between the casebook and the textbook was significant. Typical 'textbook' cases were at times noted on the pages of casebooks-patients described as suffering from a profound depression, suicidal tendencies, and delusions of guilt and wrongdoing. But just as common were cases marked by difference and individuality who corresponded poorly to the formally defined criteria of the diagnosis. Following from this, it should also be noted that one of the symptoms repeatedly emphasised by Clouston as a defining feature of melancholia-'mental pain'-was virtually absent as a descriptive term in Morningside's patient records.

A comparison between asylum case records and published literature illustrates the complex procedures and negotiations that took place when Victorian physicians attempted to define, delineate, and diagnose mental disease. It also sheds further light on one particular symptom of melancholia that was a key focus of Chapter 5: suicidal tendencies. Clouston and his peers pointed to the annual statistical reports of their institution as evidence for the growing incidence of suicidality among the insane, and in particular the overwhelming prevalence of suicidal behaviour in melancholia. While each asylum necessarily had many of its own characteristics in this period, a number of clinical and administrative features were equally shared. In large part this was a result of attempts by the Lunacy Commission to standardise practices, but the increasing move towards professional association and a sharp rise in the number of asylum physicians who published books and articles based on their clinical observations also played a significant part in facilitating an increasingly homogenous professional environment. The Scottish Board of Commissioners allowed greater managerial freedom for its asylum superintendents than did the English Lunacy Commission; however, in the case of Morningside this had the effect of bringing this institution closer to the standard practices advocated by the English Commissioners. Clouston was a prominent figure in the emerging profession of psychological medicine, he was a moderniser and a prolific publisher, inspired by the latest advances in physiological psychology and internal medicine. The Royal Edinburgh Asylum serves as a fitting space within which to investigate the role of clinical and administrative practices in the production of melancholia as an increasingly standardised diagnosis. Its records serve as the primary case study of this chapter, alongside records from Bethlem (London), Brookwood (Surrey), and Ticehurst (Sussex). As the records of these institutions 
show, significant intellectual work was required in order to forge a demonstrable correspondence between what was observed on asylum wards and what was presented in textbooks and journal articles.

\section{A Note on Asylum Records}

To describe the existing scholarly literature on the Victorian asylum as extensive is an understatement. Volumes have been written about virtually every aspect of what went on inside the walls of these institutions as well as about their place within wider social structures. ${ }^{8}$ Andrew Scull has suggested that any 'grand' or general claims about insanity can 'be adequately tested, refined, and extended only on the basis of careful case studies of a range of asylums: studies which grasp the relationship of local developments to the broader national picture, but which simultaneously exploit the opportunity offered by the possibility of a more intensive examination of the history of an individual asylum'. Elsewhere, Scull has lamented what he sees as historiography of psychiatry and of the asylum largely divided along disciplinary lines, with the 'broader scholarly perspective' having chiefly fallen within the purview of sociology while historians have tended to focus 'on the micro-politics of insanity'. 10

It has certainly been the case that many historians of the asylum have tended to favour the local; what such studies search for, perhaps, is 'not generalizable laws, but contextualised meanings of madness'. ${ }^{11}$ Scholars have made extensive use of the staggering wealth of paperwork left behind by the large pauper asylums produced by Victorian bureaucracy. From oversized casebooks, to pecuniary records, to diet tables, building plans, and both private and official correspondence, these documents with their faint odour of disinfectant and mould have allowed historians to speak about the place of the asylum in Victorian society, and the place of the patient in the asylum. Analyses of admissions records offer data on gender, class, religious persuasion, and, of course, diagnoses. Casebooks recount a plethora of 'delusions', vast amounts of drugs administered, methods of force-feeding, and recoveries, as well as conflicts, frustrations, deaths, and autopsies. Melling and Forsythe's study of the Devon county asylums briefly referred to in the Introduction sought to do what Scull prescribed-situate the local in a broader context. ${ }^{12}$ Other narrators have used asylum records to trace changing practices in a specific context, ${ }^{13}$ or 
to draw attention to previously obscured factors in admission and diagnosis, subjecting asylum records to scrutiny which seeks to problematise the data on offer rather than take the recorded figures for granted. ${ }^{14}$

Such rich histories have demystified the Victorian asylum for contemporary readers, and highlight the central role these institutions played in the foundation of psychiatry as a modern discipline and branch of medicine. Crucially, asylums were key to the development of diagnostic practices and categories. Anne Goldberg suggests that medical diagnoses such as melancholia 'present solely the voice of the physician, and an abstract voice at that. They tell us something (but not much) of medical practices at the time, but next to nothing about the patient' ${ }^{15}$ It is certainly doubtful whether much can be learnt about the patients behind the medical labels from studying asylum records, but the development of diagnostic categories was closely intertwined with medical practices in a mutually productive relationship. Diagnostic literature informed clinical practices, and vice versa, as is still the case today. It follows that a comprehensive understanding of either of these necessitates an interrogation of their relationship. While physicians presented their nosologies and noteworthy case studies in textbooks and journals, published material gives only a partial picture of the process whereby diagnostic categories were produced, refined, and standardised.

Three of the institutions whose records are drawn upon in this chapter have been the focus of rich historical studies that, taken together, illustrate the complex relationship between local practices, central directives, and theoretical works on psychopathology. ${ }^{16}$ This chapter does not, however, go into detail about the individual asylums, about life inside their walls or the people who resided or worked there. The aim in this chapter is not to say something meaningful about the people who went into the asylum and became patients, or the family members or workhouse officials who had them committed, or the physicians who diagnosed them. The concern here is with the production of psychiatric knowledge about people. As noted in the Introduction, asylum records are here read as textual sources; as a crucial component of the intellectual work that produced melancholia as a biomedical mental disease with an increasingly standardised symptomatology. While the previous chapters considered the various theoretical and administrative frameworks that were central to this process, the present chapter maps how the melancholia diagnosis was shaped as it travelled back and forth between the textbook and the casebook. 


\section{Thomas Clouston ANd The Modernisation of Morningside}

The Edinburgh Royal Asylum at Morningside offers a fitting space for interrogating the relationship between asylum case notes and published literature in the late nineteenth century. The hospital's superintendent, Thomas Clouston, was one of the period's most prolific and influential writers on mental disease, and Morningside was at the time one of the largest institutions for the insane in Britain. It admitted both pauper and private patients (at various rates), and a significant portion of its patients were admitted from across the border, from as far away as Newcastle. Morningside's medical records and the publications of its staff are the focal point of this chapter, situated in the wider context of published literature on melancholia at the turn of the century, and contrasted with case notes from three other asylums.

English lunacy law and administration were briefly outlined in Chapter 5. In Scotland, legal reform of the asylum system came more than a decade after the Lunacy Acts were passed for England and Wales. Following reports of ill-treatment and neglect, a Royal Commission was appointed in 1855 to investigate the care of lunatics in Scotland's asylums and licensed houses. The Commission concluded that abuse was widespread and drastic reform was required. ${ }^{17}$ With the Lunacy (Scotland) Act passed in 1857, a centralised system similar to the English one was created, to be overseen by a Board of Commissioners who were tasked to inspect Scottish asylum on an annual basis and ensure that standards of management, care, and treatment were upheld. ${ }^{18}$ Physicians were to submit yearly reports on the state of their institutions, including statistical tables pertaining to the asylum population. By the 1860s the British lunacy bureaucracy was largely complete, with institutions across England, Scotland, and Wales operating under similar centralised systems and regularly producing a wealth of statistical data about the patients residing within their walls. The Scottish Lunacy Act contained much the same provisions as the two British Acts, but a number of practical differences existed. For instance, Scottish asylums were more likely to house both private and pauper patients, and in some cases did not deploy these two distinct categories. There were beds available for people of various means, and Clouston took pride in Morningside's ability to provide highquality care for patients of modest middle-class backgrounds who would not qualify for subsidised treatment but who would not be able to pay 
the same rate as private patients from the higher social strata. ${ }^{19}$ Another significant, and related, difference was that two medical certificates were required for both private and pauper patients. In addition a 'petition' (later reception order) needed to be signed, usually by a relative or poor law official. All documentation would be submitted to the Sheriff who would then decide whether or not the person should be sent to the asylum. $^{20}$

Clouston took over the running of the Morningside Asylum near Edinburgh upon the death of its former superintendent, David Skae, in 1873. Clouston had received his medical training at Edinburgh, where he had studied under Thomas Laycock among others. He went on to train under Skae immediately after obtaining his medical degree, after which he was offered the role of medical superintendent at Cumberland and Westmorland Asylum in Carlisle where he remained for a decade. Clouston was the definition of a rising star among his peers-by the time he took charge of Morningside he had already been co-editor (with Maudsley) of the Journal of Mental Science for a year, and had published a number of articles on mental disease. He would go on to become one of the most prolific writers of his peer group, and remained the head of Morningside until well into the first decade of the next century. ${ }^{21}$

Clouston was firmly wedded to a modern scientific approach to mental disease, and was inspired by the work of physiologists such as Carpenter and Laycock. The latter had assumed the chair of the practice of medicine and clinical medicine at Edinburgh University in 1855, and also gave the university's lectures on mental diseases. ${ }^{22}$ When Clouston took over as head of Edinburgh's major asylum the two men made a 'private arrangement' to combine their theoretical and practical knowledge of mental disease. In a lecture delivered at the university three years after Laycock's death, Clouston praised his friend and mentor for his leading contributions in the field of 'cerebral physiology and pathology'. ${ }^{23} \mathrm{He}$ subsequently filled Laycock's role as a lecturer in mental diseases, allowing him to combine his clinical experience with the theoretical teaching of psychological medicine. Clouston's early lectures at Edinburgh formed the foundation for his first textbook, Clinical Lectures on Mental Diseases (1883).

Clouston's ascent to the position of superintendent at the Royal Edinburgh Asylum was immediately noticeable in the practice of taking patient notes. Mid-way through 1873, the system of classification used at Morningside was transformed rather abruptly, with the result that it conformed 
more closely to the standard nosology recommended by the English Lunacy Commission. As discussed in Chapter 5, in England and Wales the Lunacy Commission strongly encouraged nosological unity across asylums, urging physicians to adopt its recommended system of classification, and providing asylums with pre-printed forms for recording signs and symptoms of mental disease. However, the Scottish Board of Commissioners took a different approach, allowing physicians to choose the system they found most useful. George Robertson, Clouston's successor at Morningside, praised this decision in a 1920 historical review of the Scottish lunacy system, suggesting that it encouraged innovation and prevented stagnation. ${ }^{24}$ In the case of Edinburgh, it meant that the asylum was reformed along modern scientific lines when Clouston was appointed to run it, as he chose to steer Morningside largely along the lines favoured by the Lunacy Commission across the border.

The freedom awarded to Scottish asylum physicians in the management of their institutions meant that Skae had been able to deploy a wholly individual nosology. He had developed his own system of classification based on the presumed causes of mental disease rather than observable symptoms, divided into twenty-five categories (and two subcategories), such as 'phthisical insanity', 'post-connubial insanity', 'ovarian insanity', 'asthenic insanity', and 'traumatic insanity'. ${ }^{25}$ Under Skae's management, his own system was used in conjunction with more widely accepted categories such as melancholia, mania, monomania, moral insanity, and dementia, so that some patients received a diagnosis from Skae's system, and some received one of the more common labels. When Clouston took over in the summer of 1873, the more standard categories were immediately deployed across the board. From this point onwards, the majority of patients arriving at Morningside were diagnosed with mania, melancholia, general paralysis, or dementia, with the odd case of monomania, moral insanity, and imbecility. Skae's system was initially preserved as a secondary diagnostic tool in addition to the primary diagnosis, but gradually fell out of use.

As well as enforcing a standardised system of classification, in 1874 Clouston introduced casebooks with pre-printed headings. The old casebooks used under Skae had consisted of numbered blank pages, whereas the new ones came with several pre-printed sections with various subheadings, including basic information such as age, sex, religion, and occupation. When a patient was admitted to Morningside, the attending physician was now required to state whether there was a 'hereditary history of insanity', what the patient's 'first' and 'recent' 'mental' and 
'physical' symptoms were, whether they harboured any 'morbid habits or propensities', and whether the patient was 'suicidal' or 'dangerous'. Following these sections, the 'facts indicating insanity' given in the two medical certificates was to be entered. The second page of a new case was devoted solely to the patient's 'state on admission', requiring the attending physician to note any signs of 'exaltation', 'depression', 'excitement', or 'enfeeblement', whether the patient was 'coherent', had a reasonable 'memory', and whether they exhibited any 'delusions'. At the bottom of the page, after a long list of bodily functions to be assessed, a diagnosis was to be entered. This was followed by a separate heading asking for a second diagnosis according to 'Skae's classification'; this space was, however, for the most part left blank.

The information entered on the first two pages of each new patient's records constituted the foundational data for the statistical report compiled by Clouston and submitted to the Board of Commissioners on a yearly basis. He composed Morningside's annual reports with impressive breadth and detail, and included his own analytical discussions of the statistics presented therein. ${ }^{26}$ Clouston's meticulousness and emphasis on rigorous standards and consistency in recording practices were made explicit in his first report to the Board of Commissioners at the end of 1873:

On the admission of every patient, as complete a medical history of the causes of his disease, and his previous symptoms, as can be obtained from the person who accompanied him from the Asylum, is taken down by one of the Assistant Physicians, who then examines carefully into the symptoms present, and afterwards keeps a record of the changes that take place. This procedure I regard as of the utmost importance to the patient in every way, if done thoroughly and systematically. I have brought into use for the purpose printed forms with suitable headings, so that nothing may be omitted in any case. ${ }^{27}$

These 'printed forms', then, ensured that certain types of information were noted in every case. The presence of pre-printed headings also meant that it was possible to note various aspects of the patient's condition with a simple 'yes' or 'no', or with other brief affirmative or negative responses. Thus, the attending physician only had to give a single word answer to questions of whether the patient was 'suicidal' or exhibited signs of 'depression'. The forms left the choice of diagnosis open-ended; 
thus, while Skae's nosology was no longer used as a source of primary diagnoses, the statistical tables of diagnostic categories would change subtly from one year to the next. Certain types of mental disease featured in every annual report, specifically mania, melancholia, general paralysis, and dementia, with the first two being further divided into a number of subcategories. In the first report under Clouston, we find in addition twelve cases of 'moral insanity' and one case of 'monomania' among the new admissions of that year. As noted above, the following year Clouston remarked upon a notable increase in the number of melancholic patients admitted, suggesting that this development was 'very striking, and of great interest', emphasising the importance of vigilance in the face of the persistent suicidal tendencies of such patients. ${ }^{28}$

For the year 1874, 67 patients were reported to be 'suicidal', of whom 38 were diagnosed with some form of melancholia. In a detailed analysis of the annual reports of Morningside, Allan Beveridge suggests that Clouston recognised eight subtypes of melancholia: 'simple; hypochrondriacal; delusional; excited; restive; epileptiform; organic; and suicidal and homicidal'. ${ }^{29}$ The categories Beveridge lists are drawn from Clouston's Clinical Lectures on Mental Diseases. However, the categories presented in the book took some time to refine. In 1874 we meet with some additional subtypes of melancholia which appear to bear the traces of Skae's classification, such as 'traumatic', 'puerperal', 'senile', and 'melancholia of lactation'. ${ }^{30}$ Between 1873 and 1900 melancholia was gradually and subtly standardised in Clouston's report to the Board of Commissioners. Certain subcategories disappeared and others became more common. At the same time, the 'very striking' proportion of melancholic cases which prompted Clouston's comments in 1874 would from thereon become the norm; indeed the most striking thing about these figures is perhaps that while melancholia continued to be diagnosed with growing frequency, Clouston never again remarked upon this development.

\section{A 'Typical' Case of Melancholia}

The description of melancholia offered by Clouston in Clinical Lectures was clear and precise: it was an illness characterised by 'emotional depression' and 'mental pain', often leading to 'uncontrollable impulses towards suicide', and sometimes accompanied by a 'loss of self-control' or 'delusions', a lack of interest in a capacity for most common activities, and with slowed bodily functions. Like Griesinger, Clouston placed melancholia 
under the banner 'states of mental depression', which he also referred to as 'psychalgia', fusing to an extent the symptoms of depression and mental pain in the same way Griesinger had done. Moreover, like the German psychiatrist had also done some decades earlier, Clouston emphasised that these states were 'of all forms of mental diseases those that are nearest mental health'. Following from this, he highlighted mental pain as a particularly interesting symptom, as this was a sensation also experienced by healthy people:

To be able to feel pain implies an encephalic tissue for the purpose. To be very sensitive to pain implies that the tissue is acutely receptive of impressions. So with mental pain there can be no doubt that the healthy physiological condition of the encephalic tissue in the brain convolutions through which ordinary or mental pain is felt is one between extreme callousness to impressions and extreme sensitiveness. A man in robust health, well exercised, does not feel pain nearly so acutely, and bears it better than when he is weak and run down. Those principles apply equally to the feeling and bearing of mental pain. To experience emotion at all to feel - implies an encephalic structure for this purpose. The most casual study of the affective capacity in humans show us that it differs enormously in different persons. ${ }^{31}$

Added to a brain's level of sensitivity was its inhibitory power-its capacity for enduring pain. These two aspects of the cerebral physiology of pain together held the key to understanding the potential ability for mental pain to become pathological: 'when a brain is sensitive, and has little inhibitory power, this combination is a source of weakness and of disease'. ${ }^{32}$ Such mental pain was a defining feature of melancholia, a diseased state that could be easily distinguished from 'a mere feeling of melancholy' since a 'typical case of melancholia [...] runs a somewhat definite course, like a fever, and has often all the characters of an acute disease'. ${ }^{33}$ Clouston suggested that melancholia was by far the easiest form of mental disease to examine and diagnose, as patients were generally aware of their suffering and able to communicate it and answer questions. At the commencement of an examination, he suggested, the melancholia patient 'will tell you in the first place very likely that he is unhappy, and feels mental pain and depression'. The 'unsoundness of mind' would manifest when asking patients for the cause of this suffering, as they would almost invariably 'assign as a cause of their misery what is not its cause at all'. ${ }^{34}$ However, as will be seen below, there was no 
mention in the Morningside casebooks of patients themselves using the words 'depression' and 'mental pain' to express their emotional state.

Any student consulting Clouston's textbook would be furnished with clear instructions for how to identify melancholia: look for the expression, in words and countenance, of mental pain and depression, a general lack of interest, and be attentive to any signs of suicidal intent. Moreover, patients would most likely attribute their suffering to an illusionary cause, such as having committed a terrible sin. Cases of simple melancholia, by far the most common, would rarely be sent to the asylum as they could be treated at home, but were nonetheless important to identify and diagnose to prevent deterioration of the condition. In these cases, 'the affective depression or pain is far more marked than the intellectual and volitional aberrations'. ${ }^{35}$ Clouston presented a 'typical' case of this form of the disease, a gentleman in his sixties whose emotional health had begun to decline following 'a big piece of intellectual work'. He became tired, depressed, lost interest in his usual duties, and was unable to feel the same affection for his wife and children as he had previously done. Confused by these feelings, he believed that they 'must be a judgement on him for some sin'. With time his mental suffering grew more severe, his delusions of guilt more profound, and his whole constitution became affected. Upon examining the patient, Clouston recommended rest, a journey to the sea, and an 'easily digested but fattening diet'. ${ }^{36}$

Clouston supplemented this case with a line of similar 'typical' cases of simple melancholia, followed by the closely related hypochondriacal variety, before proceeding to the more profound, 'delusional' melancholia. Contrary to Maudsley, Clouston found the suicidal propensity to be more common in this than in the simple form, as the mental suffering was usually more severe. In these forms of delusional melancholia, Clouston argued, many patients experienced real or imagined abdominal discomfort, often resulting in a refusal of food, which in the most critical cases could only be resolved through force-feeding with the stomach pump. He recounted a number of such typical cases, characterised by profound depression of mind, delusions both of a religious and a hypochondriacal nature (pertaining to the gastric region), persistent suicidal tendencies, and a refusal of food leading the patients to be forcefed. With some variations, the similarities with Moses B., the typical case of suicidal melancholia met with at the start of this chapter, are striking. ${ }^{37}$ 
However, Clouston also noted a type of melancholia-Excited (Motor) Melancholia - that exhibited some more uncommon, markedly excited, features, resulting from 'epileptiform attacks'. Such involuntary reactions were attributed to the relationship referred to above between the brain's sensitivity and its inhibitory power, whereby a combination of an intense response to stimuli and a lack of cerebral inhibition resulted in violent involuntary motor reactions. This type of melancholia was particularly common in 'the Celtic race' and in women in general, Clouston argued, illustrated by the 'wailing and weeping, the gesticulations and motor grief of an Irish woman', reactions that were 'usually out of all proportion to the mental pain'. Recounting a typical case of this form of the disease, Clouston described the familiar symptoms of melancholia, suggesting that the female patient 'attempted suicide', was upon admission 'greatly depressed', and 'confessed to feeling exceedingly miserable'. After a few days in the asylum her depression grew deeper, and she 'thought she was to be killed, and that everything was going wrong with her; did not take her food well; attempted to drown herself by jumping into the asylum shallow curling pond'. The excited motor features were exhibited as an expression of her despair: 'She wrings her hands; sways backwards and forwards, contorting her body; rushes about from place to place, and cannot settle for a minute'. 38 Again the reader was presented with a typical case featuring all the usual symptoms of melancholia, but with the added aspect of involuntary motor action arising from, and reflecting, the particular quality of this mental disturbance.

In a lecture delivered to the asylum staff a few years later, in 1887, Clouston reiterated his earlier definition of melancholia as predominantly characterised by mental pain, suggesting that "[1] ove of life is a natural instinct, but when the brain is diseased, as in Melancholia, the love of life is lost. Melancholia is the least marked kind of insanity; every kind of insanity begins with it as the first symptom. The feelings, intellect, \&c., are all disturbed, and the chief symptom is mental pain'. ${ }^{39}$ Like many of his peers, Clouston held this mental pain to be a significant cause of the suicidal propensity in melancholia. He emphasised that 'while no tendency to suicide exists at all in many melancholics', it should nonetheless always be carefully watched out for since 'it does exist in some form or other, in wish, intention, or act, in four out of every five of all the cases'. ${ }^{40}$ Nevertheless, Clouston found it useful to note a separate category of 'suicidal melancholia' closely related to a less common 'homicidal' type. This type of the disease was, he argued, 'the most striking and most 
important'. In a remark similar to those made by Maudsley and Mercier a few years later, ${ }^{41}$ Clouston perceived suicidality as a complete reversal of the evolutionary drive for self-preservation:

When the love of life, that primary and strongest instinct, not only in man, but in all the animal kingdom, through which continuous acts of self-preservation of the individual life of every living thing take place, when that is lost, and not only lost but reversed, so that a man craves to die as strongly as he ever craved to live, we have then the greatest change in the instinctive and affective faculties of man that is possible, and have reached the acme of all states of mental depression. ${ }^{42}$

However, like Maudsley and Mercier, Clouston went on to note that this utter reversal of the natural instinct could, paradoxically, at the same time constitute a natural, indeed sane reaction when occurring as a response to profound mental pain. 'The determination to commit suicide is in some cases one come to in the calmest and most reasonable way', he suggested, and in such instances was 'nearest in character to the suicides among sane persons'. However, in a large number of cases of melancholia, the suicidal tendency was equally bound up with severe and frightening delusions arising from mental pain and depression, most often delusions of guilt tied to the belief that the patient had committed a great sin against God and her or his family and friends, and therefore did not deserve to live. The suicidal tendency in melancholia was thus a feature of the disease that much preoccupied Clouston, not just from the point of view of patient safety, but also as a riddle in the philosophy and biology of life. This interest in suicidality was much in evidence both in his annual reports to the Board of Commissioners, and in the way patients' symptoms were assessed and noted in the Morningside casebooks. Indeed, most of these distinctions between different types of melancholia listed in Clouston's published work and annual reports were not made in the Morningside casebooks, with the exception of suicidality. The single diagnosis would be entered, and often followed by an abbreviated reference to suicidal tendencies in brackets. The notes made as to a patient's suicidality would be tallied up at the end of the year and entered into neat columns listing the total number of 'suicidal' patients, which diagnoses were represented among them, and how many had 'meditated' or 'attempted' suicide. Through these different acts of recording, counting, summarising, and listing, then, a vast range of activities and expressions communicated and 
observed on the wards created two categories that featured in reports and published literature, not just in Edinburgh, but across Britain-the 'typical' case of melancholia, and the 'suicidal' patient. A closer look at asylum records reveals that both categories suggested simplicity and coherence that was not mirrored in the myriad of symptoms displayed by asylum patients who received these labels.

\section{Typical and Untypical Cases: Melancholia FROM THE TeXTbOOK TO THE AsYlum WARD}

In the final decades of the century, an increasing number of asylums introduced casebooks with pre-printed sections for recording patient history, symptoms, and diagnosis. This formed part of, and helped facilitate, a broad shift in record taking from longer, discursive descriptions of patients' mental states to briefer statements and descriptive keywords. Two concerns in particular drove this development. On the one hand, the requirement to provide uniform and comparable statistical data on patient populations and diagnostics produced a need for standardised recording practices. On the other hand, these changes to how patient data was recorded were also facilitated by time constraints at a time when asylums and their populations were rapidly expanding across the country. This shift in the practice of note-taking was mirrored across much of Western medicine in the second half of the nineteenth century; a development that one historian has referred to as a 'new epistemological and aesthetic sensibility, expressed as a narrative preference for what was universal and precise over what was individual and discursive'. ${ }^{43}$

The casebooks at Morningside illustrate this shift. In earlier years, under Skae's management, case notes had been comprehensive, discursive narratives of each patient's history, state of mind, and bodily condition. With the pre-printed casebooks introduced by Clouston in the 1870s, a few key terms were often deemed sufficient. While the amount and format of the information entered varied, sometimes considerably, depending on which physician entered it, the overall trend was towards briefer, more precise descriptions, centring on single words or abbreviated sentences. The trend for briefer language was particularly prominent in the description of symptoms. The act of condensing information was notable in the 'facts indicating insanity' transferred from the medical certificates to the casebook, where the explanations given by the two certifying physicians were increasingly summarised into a few keywords. In the case of 
Isabella K., a rather typical case of melancholia admitted in the summer of 1893, the first of the medical certificates accompanying her to the asylum suggested that the patient 'talks incoherently and has delusions that she has ceased to live. She does not know the year nor the day of week. Has great depression. Melancholia'. Added to this were the 'facts' told by her husband, who was said to confirm this assessment of her mental state, adding that 'she has been ill for about ten days and has lost her memory'. The second medical certificate claimed Isabella K. to be 'very depressed and melancholic, says that she is lost and that her maker has devised a punishment for her disobedience to his will to be burning in Hell', and that 'her husband states that for ten days she has been very depressed, forgetting everything, 44

On the first page of her casebook entry, this already brief information about the patient's state of mind was entered under the heading 'Facts of Medical Certificates' simply as 'Looks depressed. Delusions. Bad memory'. She was further noted as 'suicidal' and where the physician was required by the pre-printed headings to note the presence or absence of 'depression', the answer given was 'Considerable. Looks unhappy'. It was not stated in what her suicidal tendency consisted, except in the single word 'threatened'. ${ }^{45}$ Overall the format of casebook entries under Clouston's management produced these kinds of brief, concise descriptions where patients' mental states were described as key symptoms, such as 'depression', 'delusions of a religious nature', and so on. This practice had the effect of creating an increasingly homogenous set of symptoms, as the more personalised narratives of individual patients were gradually erased. We meet, then, with a large number of 'typical' cases of melancholia, similar to that of Isabella K. above, and of Moses B., the young suicidal doctor whose case was discussed at the start of this chapter.

One such typical case, fifty-five-year-old Dorothy D. admitted in 1876, was described in the following terms: 'Became depressed and melancholy', 'Refused Food', 'Has attempted suicide several times; by knife, hanging, \&c. and wishes to drown herself'. 'Is very depressed in spirits, and imputes blame to herself for all sorts of imaginary sins'. Her state of mind upon admission was noted as 'Depression great - shown by her conversation and the expression of her countenance; says that she has ruined her husband and family, that she injures and destroys everything near her, that she has done great wrong, \&c'. Such typical cases of melancholia abounded; individuals who came into the asylum and ticked most of the boxes for common forms of melancholia: mental depression, 
suicidal tendencies, and religious delusions, but who were generally clearheaded enough to answer questions and express how they felt. Pauline $\mathrm{N}$., admitted in the same year as Dorothy, was an equally typical melancholic, her most prominent mental symptoms noted as 'depression and suicidal tendency', and according to both of the certifying physicians believed herself to be 'under a curse from her birth', due to which she had 'ruined her family'. Her state upon admission to Morningside was recounted as characterised by 'great depression shown by her depressed self-absorbed expression and demeanour'. Twenty-five-year-old Margaret L. was an equally typical case, having become 'depressed' as a result of 'anxiety' relating to her work. An assistant in her grain merchant father's business, the exciting cause of her melancholia was believed to be her sister's recent move to America, 'throwing the whole charge of business on her'. Described as 'suicidal', one of the physicians certifying her lunacy stated that she had declared 'that she wished to destroy herself, that she may not be a burden to her parents', adding that according to her father 'she took poison on Thursday, and this morning she threw herself over the window from a height of three flats'. When first examined upon her arrival at the asylum, her mental state was given as one of 'considerable depression, shown by her expression, and by her conversation. She says she wishes to destroy herself, as she is the cause of ruin to her father'. ${ }^{46}$ Similarly, Alexander H., admitted in 1877, was described as 'depressed' and 'low in spirits' and having 'attempted suicide by taking laudanum'. The attending physician at Morningside assessed his mental condition as 'Depression great, shown by his expression, manner, and conversation, and by the nature of his delusions. Says that he feels very dull and that he is lost forever'. 47

Apparently absent from these and many more 'typical' cases were, however, any account by the patients themselves of suffering from 'depression', or from 'mental pain'. Indeed, the latter did not feature as a symptom in the Morningside casebooks at all. What these casebooks reveal, then, is the process, today standard practice in psychiatric diagnostics, of translating patients' various complaints, verbal and nonverbal expressions, past and present acts, and reported medical history into certain symptom terms - universally applicable keywords that serve to merge together the chaos of human activity into simplified medical labels. With a rapidly growing asylum population, and a perceived need for a more unified language between medical psychologists, the increased use 
of unifying keywords such as depression and mental pain served important practical uses for late Victorian asylum physicians. It enabled swifter description and recording of a patient's mental state, as well as facilitating the assembly of statistical tables over diagnoses and symptoms. It also aided the dissemination and publication of cases within the wider peer community by producing a nomenclature that was accessible and comprehensible to anyone with professional knowledge in the field of mental disease. When one physician published an article about a particularly interesting or representative case, such as that of Moses B., the use of terms such as 'suicidal' and 'depressed' would immediately make the patient's state of mind appear familiar to the professional reader.

However, while the act of merging an endless range of human activities into simplified key terms made descriptions of symptoms and diagnoses of disease more precise, it equally served to flatten out a highly uneven field of psychological phenomena. The use of singular keywords precluded the need for more detailed narrative descriptions of individual experiences-one of its greatest benefits to the busy physician, but equally an act that had the effect of producing new information about people. As noted above, in the decades following Clouston's ascendancy to the position of superintendent at Morningside, the casebook descriptions grew increasingly brief and concise, and included less and less variation in the terminology used to note the patients' mental states. One of the shifts that took place with the introduction of pre-printed headings was a decline in reasons given for assigning a particular symptom. In other words, descriptions became decidedly $u n$-descriptive. This was particularly the case with 'depression', one of the key features that required noting as part of a new patient's state upon admission. In the case of Dorothy D. referred to above, her 'depression' was observed in 'her conversation and the expression of her countenance'. Similarly, Janet G.'s 'depression' was described as 'Great, looks very unhappy, cries', ${ }^{48}$ Alexander Duffle's depression was noted as 'Great. Expression is one of misery and he is continually crying', ${ }^{4}$ Jane Ann C.'s depression was 'exhibited in manner, appearance, and communication', Isabella Hutton's depression was 'marked, exhibited in appearance and conversation', ${ }^{50}$ Robert G.'s depression was 'Considerable. Looks unhappy and confused, and cried while being examined', 51 and Catherine G.'s depression was simply 'present in her expression'. ${ }^{52}$

Contrary to Clouston's remark in his textbooks, patients did not themselves appear to express a feeling of being 'depressed'. As noted above, depression, mental pain, and suicidal tendencies were descriptive 
terms deployed by physicians as identifiable symptoms, keywords to describe a certain state of mind that was perceived as widespread among asylum patients, but which said little about what those patients themselves expressed about their emotional states. David Walker and Anita O'Connell have noted the homogenising function of depression as a single descriptive term for a range of emotional states associated with low mood, remarking that it 'not only replaced a wider vocabulary for a variety of experiences', but that it 'also flattened out the individuality' of those experiences. ${ }^{53}$ Only fragments of individual expressions can be glimpsed in the brief narratives given of patient interviews, where a vast range of thoughts and feelings were described. John W., whose depression was stated as 'marked', expressed according to the attending physician a fear 'that the persons around him are wishing to injure him, and is constantly crying out "You won't kill me, you won't kill me", 54 whereas Elizabeth $\mathrm{F}$. told the medical officer examining her that she believed herself to have been poisoned as a result of 'some sin she committed in her youth', and that she was now eternally lost. ${ }^{55}$ Isabelle $H$. expressed that 'she is not human, that she has no feelings and that she would like to die', ${ }^{56}$ and Peter S. claimed that 'the devil is after him and that people are suspicious of him'. Other patients said very little at all, appearing reluctant and unable to answer any questions put to them. Robert M., a pauper patient admitted in 1887, would 'not answer any questions or answers them incoherently, constantly repeats the same words, as "the man", "the man", 57 while Isaac W. was described as 'taciturn and disinclined to answer questions', ${ }^{58}$ and Isabella M. 'Refuses to answer all direct questions' and displayed a 'vacant look'.59

This conflation of different expressions under the label depression was equally reflected in the casebooks of other British asylums in this period, such as Surrey Country Asylum at Brookwood, which was run by Thomas Brushfield. The casebooks at Brookwood tell a similar story to those of Morningside, and contain a large number of typical and untypical cases of melancholia. Frances H., a 38-year-old nurse admitted into Brookwood in 1879 and diagnosed with melancholia was recorded as suicidal and suffering from 'depression of spirits without apparent cause', which manifested in that she 'does not know what she shall do and feels suicidal' and 'is not regular'. ${ }^{60}$ Julia P., a young woman admitted into the same asylum the previous year was also recorded as depressed and suicidal with 'religious delusions'. The evidence for her mental state consisted in that she 'said the Devil was constantly after her and that 
she feels as if she must kill herself ${ }^{61}$ Similarly, William W., who was brought to Brookwood from Lambeth workhouse in 1871, was described as depressed, 'very' suicidal, and having 'delusional views of religion', which led him to believe that 'there is no time for him left to repent and that his sins have been so great'. ${ }^{62}$ Like Morningside, Brookwood had recently introduced casebooks with pre-printed sections, which made it easier for attending physicians to record mental symptoms, in particular the presence of suicidal tendencies, where a simple yes or no was sufficient. Suicidality appeared with high frequency in conjunction with the melancholia diagnosis, which was reflected in the asylum's annual statistical reports. Depression on the other hand was not included in the pre-printed section (unlike at Morningside), but it was nevertheless by far the most frequently noted mental symptom in melancholic patients alongside suicidal tendencies.

A similar picture emerges from the casebooks of Ticehurst, a private licensed facility in Sussex run by the Newingtons, a family of physicians, and where Henry Maudsley occasionally consulted. While private institutions were subject to inspection, they were not under the same administrative pressure as county asylums with regard to data collection. However, recording practices generally mirrored those of public institutions. By the mid-1870s, pre-printed casebooks were also in use at Ticehurst, which asked among other things whether the patient admitted was suicidal. Depression equally appeared as the most common mental symptom of melancholia, such as in 44-year-old John S., whose 'depression of spirits' was noted as 'great' and evidenced by 'constantly thinking \& troubling about his business \& money' and that 'he is unable to fix his attention on anything \& that he said last night "you don't know what I am going to do"'. This statement by the patient appears to be the primary reason for suspecting him to harbour suicidal tendencies, alongside a 'refusal of food and medicine'. 42-year-old Caroline Ann W., admitted three years later and diagnosed with melancholia, was equally described as suffering from 'mental depression' and recorded as suicidal. She was reported as stating that 'she was the devil and not fit to live' and that she 'took poison \& attempted to destroy herself'. Alongside such 'typical' cases of melancholia with what was at the time familiar signs of 'depression', can be found others such Eliza B., a young woman admitted in the autumn of 1878 and diagnosed as 'melancholic and suicidal', with her mental state described as 'very depressed'. In this case, none of the more common reasons for this term are given, rather the evidence for her 
depression appears to be that she 'won't eat any meat as she believes she is then responsible for the death of the animals'.

\section{Suicidal Melancholics}

As the above cases imply, a number of different expressions and acts suggested to physicians that melancholic patients were depressed, and that they harboured suicidal intentions. In several of his reports to the Board of Commissioners, Clouston remarked upon the growing incidence of suicidal patients under his care, and as suggested above, his annual statistical charts included a table of suicidal tendencies in patients admitted. The total number of suicidal patients was divided into the various forms of mental disease represented, followed by a list of the nature of attempts, where such had been undertaken. Each year the tables indicated that the vast majority of suicidal patients, whether they had 'attempted' or 'meditated', were diagnosed with melancholia. However, when taking a closer look at the patient records that served as the basis for these tables a rather more complex picture emerges.

In his 1887 report to the Commissioners, Clouston emphasised the importance of vigilance in order to prevent 'suicidal' patients from achieving their goal. While deaths by suicide were rare in Morningside (and generally also in other asylums), this year two patients had succeeded in taking their lives, prompting Clouston to reiterate the substantial difficulty for even the trained physician in detecting the presence of suicidal intent in a patient:

We have no test by which we can infallibly tell the presence or absence of the suicidal impulse - that most subtile, terrible, and sudden of all morbid mental symptoms. It may exist in a man whose mental working is otherwise strong: it may arise in a moment: it may be suggested by any means of taking away life: it may overmaster the strongest resolutions and the best principles; and it may even co-exist in the mind with a horror and loathing of itself. ${ }^{63}$

That year, the number of 'suicidal' patients numbered 79, of whom 61 were melancholic. Of the total number of suicidal patients, 23 were stated to have attempted and the remaining 56 meditated. The types of attempts listed for that year were 'precipitation', 'cut-throat', 'poisoning', 'hanging', 'strangulation', 'drowning', and 'starvation'. ${ }^{64}$ 
One of these suicidal melancholics was Jane C., who had reportedly become insane following 'domestic bereavement'. She 'grew dull and low spirited', and more recently had become 'very restless and excited and tried to throw herself over the window'. Jane, then, belonged to the category of 'attempted' suicides, and was upon admission described as suffering from 'great depression' and plagued by the delusional belief that 'she has committed unpardonable sins and must go to hell' ${ }^{65}$ She was a typical case of suicidal melancholia, much like the published case of Moses B. Moses had, as noted at the start, been admitted to Morningside after taking 'a poisonous dose of Belladonna', an act that saw him labelled 'suicidal' on his reception order and medical certificates and consequently subject to close monitoring on the asylum ward. According to assistant physician Joseph Brown's article on the case, as well as Moses' casebook entries, his suicide attempts continued once inside the asylum. There, he swallowed several stones, after which he complained of abdominal distress and began to decline his meals. This act of 'refusing his food' was looked upon with severity, as it was undertaken 'evidently with the hope of starving himself'. As a result, the stomach pump was deployed on several occasions. Moses' next suicide attempt reportedly consisted in taking 'an overdose of alcohol', a feat he accomplished after having saved up the small drop of whiskey patients were given with their evening meal each night. Around two weeks after this incident, from which he subsequently recovered, the patient 'snatched' from an attendant a bottle containing 'a solution of guttapercha in chloroform', which he proceeded to drink. Moses became unconscious and only came to several hours later after persistent attempts to revive him. According to Brown, the patient grew steadily stronger over the next few days, but 'continues to refuse his food, and has to be fed with the tube'. The persistence with which Moses apparently pursued his desire to die constituted a demonstrable example of the suicidal tendency in melancholics-so determined did the patient seem in his suicidal convictions that 'his one and only object in life is to destroy it'. ${ }^{66}$

In this one single case, then, a number of acts were presented that were merged under the 'suicidal' banner-swallowing of stones, refusing food, drinking a large quantity of alcohol, and swallowing a poisonous substance. A look at similar 'typical' cases of suicidal melancholia widen the range further. Pauline N. had 'threatened or attempted violence to herself by drowning at the first attack, and during the second by swallowing pins and knocking her head', while Elizabeth F. had 'refused 
food: saying that she did not want to live' and had according to her husband 'attempted to poison herself' ${ }^{67}$ Isabella M.'s suicidal tendency consisted in 'trying to leave the house in the night, and often refusing her food', John C. had 'twice attempted suicide by cutting his throat', Isabella $\mathrm{H}$. was deemed suicidal because she would walk 'about the streets in a depressed state - found standing on the top balcony to jump over, \&c.', and Agnes F.'s suicidality manifested in proclaiming that she was 'desperately miserable and that all she wants is to leave this world'. ${ }^{68}$ Robert A., an 'anxious and dejected' widower was labelled suicidal due to having reportedly 'threatened to cut his throat, and has tried to get out of the window', Alexander M. was deemed by one of his certifying physicians to be suicidal after he 'wanted to get a knife', and Jane C. was noted as having 'threatened' suicide after she 'wandered away to the Dean Bridges' but did not jump in the river 'as she says the water was not deep enough'. ${ }^{69}$ Alexander D. was described in his case notes as having 'attempted' suicide after having become 'very excited'. While in this state he 'appeared to be suicidal and took hold of a knife. He did not injure himself however'. Robert G. was placed in the category of melancholics who had 'meditated' suicide after he 'asked for a pistol and a rope to destroy himself', as was Alexander B., who 'said that he was tired of life and wished to have done with it, but he has made no actual attempts'. ${ }^{70}$ Madeleine M., another case of typical suicidal melancholia, had reportedly been 'refusing food' and 'threw herself before a train', and Catherine G. was described as 'suicidally inclined' after stating 'that she wishes to die' $^{71}$

In the case of several melancholics who received the label 'suicidal', either in their medical certificate or upon admission, no apparent reason was given for their suicidality; rather, it appeared to be deduced from their general state of mind. Annie V., a 'suicidal' melancholic admitted in the summer of 1898, was noted as harbouring 'melancholic ideas. Thinks there is no food for her children, that she will be had up for ill treatment, \&c.', but no other reason for her purported suicidality was given. Similarly, in the case of Elizabeth R. who was admitted the previous winter and reportedly required 'constant watching', the suicidal tendency appeared to be derived from reports that she 'wanders about at night' and 'refuses food'. Refusal of food was equally the reason given for the suspected presence of suicidal intent in Jane Ann C., while in the case of Isabella H. no apparent reason was given beyond the 'usual' symptom of 'depression', deduced from the patient appearing 'dull and 
melancholy and despondent'. In a number of such cases where the 'suicidal' label came without explanation, such as those of James C. and James W., both admitted in 1888, few symptoms were given beyond the familiar 'depression', 'lowness of spirits', and 'despondency'. ${ }^{72}$ In sum, the Morningside casebooks appeared to confirm the belief expressed by Maudsley in 1879 , that '[s] uicidal feelings and attempts are common in melancholia, so much so that one suspects their actual or possible existence even when they have not been openly manifested'. ${ }^{73}$

A similar picture emerges from county asylums in England at this time. As noted in Chapter 5, Thomas Brushfield lamented the flawed nature of statistics on suicidality, suggesting that these often included self-injurious acts committed without suicidal intent. In the case of melancholia, however, he took a different approach. As with Morningside, melancholic patients under Brushfield's care were frequently labelled suicidal even in the absence of suicidal acts or openly manifested intent. In the case of John G., a suicidal melancholic admitted to Brookwood shortly after Brushfield took over the running of the asylum in the 1860s, no specific reason was given for considering him to harbour suicidal tendencies, beyond the patient stating that 'he feels very low sometimes but cannot give any reasons for being so' ${ }^{74}$ In patients diagnosed with melancholia, any act or expression that could be construed as having selfinjurious intent was likely to be labelled suicidal. Ann F., admitted in 1869, was labelled as suicidal because she 'seemed very much depressed and expressed an intense feeling of melancholy, as if she would do herself an injury'. ${ }^{75}$ Ann W., admitted the following year, was also considered to be suicidal, which according to the attending physician manifested in 'persistent refusal of food', while Sarah Elizabeth L. was said to have 'attempted suicide by pressing her fingers slightly round her throat', and for this reason required 'constant watching'. 76

The previous chapter noted how George Savage equally questioned the validity of statistics on suicidal patients, arguing that many of the suicidal patients under his care were not 'actively' suicidal. By the 1870s, Bethlem was also using pre-printed casebooks, which only required a yes or no as to whether a patient was suicidal. On the pages of Bethlem's casebooks can equally be found a range of acts and expressions merged under the suicidal label, and much as at Morningside and Brookwood, patients' behaviour appeared to be more likely to be labelled suicidal if they were considered to be suffering from melancholia. For instance, Sarah M., admitted in December 1878, when Savage had recently been 
put in charge, was perceived as suffering from melancholia with typical religious delusions, stating that she had committed 'the unpardonable sin' for which she could 'not be forgiven'. Her suicidality appeared to be attributed to her having 'made several attempts to set fire to the house'. In the case of Alfred N., another suicidal melancholic, his perceived suicide 'attempt' consisted in 'having swallowed...shilling pieces last week, and a penny this morning'. Emma $\mathrm{H}$. was described as labouring under 'extreme depression', believing herself 'to be the most wicked woman in the world'. When she drank 'some liniment', this was seen as an act with suicidal intent.

While a diagnosis of melancholia was likely to result in an assumption that the patient was suicidal, there were at times also more practical reasons for applying both labels to patients. Records of patients transferred to Morningside from St. Cuthbert's, the local poor house, tell a story of difficult to manage patients who were not reported to express any of the usual symptoms of melancholia, including intent to commit suicide, but who were admitted with 'suicidal' against their name and given a melancholia diagnosis. The question of whether to treat lunatics in the poor house infirmary or have them transferred to the asylum was a contentious one; county asylums were generally much better funded, staffed, and equipped, but it was also more costly to care for patients in these institutions, and transfers of pauper lunatics from the workhouse to the county asylum generally needed to be motivated by the inability of staff in the former to care for the person in question. ${ }^{77}$ One of the most common ways of doing this was to confirm on the medical certificate and reception order that the lunatic was either 'dangerous' or 'suicidal'. One such case was that of Mary S., admitted from St. Cuthbert's in June of 1888. None of the usual symptoms of melancholia was noted, except that she 'refuses food'. She was described as excited and 'noisy' by a nurse at St. Cuthbert's infirmary, who also reported that Mary 'tries to bite and requires several women to hold her down', and that she was 'requiring restraint by the attendants to prevent her doing mischief and injuring herself in wild attempts to leave the place'. ${ }^{78}$ In the case of Robert M., transferred from the same poor house the previous year, commonly described symptoms of melancholia were equally notable by their absence. Little information was given in the case notes as to the reasons for his confinement and for the diagnosis, only that he had 'a depressed expression' and is in a constant state of restlessness, always trying to take off his clothes and fumbling with his hands'. His medical certificates and reception order, however, cite the facts indicating insanity 
recounted by the nurse at St. Cuthbert's, who claimed that Robert was noisy and restless at night, disturbing the other patients in the infirmary, and that he 'works at the bedclothes with his hands and has to be put under restraint'. ${ }^{79}$

As these case studies illustrate, a vast number of different acts and expressions came together to produce the single category 'suicidal', a symptom of melancholia that functioned together with the other most commonly deployed keyword, 'depression'. These two symptoms of mental disease were produced from a chaos of activities, often deduced in part from 'delusions' of guilt and sin-the 'religious delusions' discussed in Chapter 5-or from a patient's 'dull' or 'despondent' demeanour, and from various acts and statements that were interpreted as intent to 'do away with oneself'. The two things most often expressed by melancholic patients themselves, according to their medical notes, were a sense of profound guilt, of having done something terribly wrong, often causing harm, shame, or destruction to one's family, and following from this, a belief that one did not deserve to live and must therefore destroy oneself. No patient was reported as uttering the words 'depression', 'mental pain', or 'suicide'. These are, however, the key features that emerge from the case notes, and from the annual reports to the Board of Commissioners, where the persistent suicidality of Morningside's melancholics was repeatedly emphasised by Clouston as one of the greatest challenges facing the physician in charge of an asylum.

Clouston's statistical tables of the frequency with which 'suicidal propensities' were encountered in the Morningside patients illustrated what had by the 1880 s become the standard view among British asylum physicians: of all lunatics melancholics were the most suicidal, and of all suicidal patients the majority were melancholics. Clouston took care to emphasise this feature in his textbook, warning students and fellow practitioners that

[t]he question of the patient being suicidal should never in any case of melancholia be left unconsidered, and the risk of his becoming suicidal should never in any case be left unprovided for. No tendency to suicide exists at all in many melancholics from beginning to end of their disease, but it does exist in some form or other - in wish, intention, or act - in four out of every five of all the cases, and we can never tell when it is to develop in any patient. ${ }^{80}$ 
His own statistics supported this claim year after year, yet no self-inflicted death was reported at Morningside until two suicides were recorded in 1879. Overall such cases were rare in Edinburgh and elsewhere, but the expectation of suicide formed a constant preoccupation for asylum physicians as well as for English and Scottish Commissioners in Lunacy. Thus, Clouston echoed the anxiety felt by many of his peers when he remarked that ' $[t]$ he fear of it in reference to some one is always more or less present in my mind' ${ }^{81}$

Nevertheless, Clouston expressed the same kind of scepticism about the reliability of statistics on suicidality as Savage and others had done. In the first (1883) edition of his textbook he subjected the statistics he had accumulated during his time at Morningside to closer scrutiny. As noted above, Clouston's tables of suicidal patients had separated those who had 'attempted' from those who had 'meditated' suicide. Of the last 729 melancholic patients who had been admitted to the institution, the tables indicated that 'four out of five...were more or less suicidal'. However, many of the attempts, he suggested, 'could scarcely be regarded as being very serious'. Moreover, of the total number just below forty per cent came under the heading 'meditated', in other words they 'had spoken of suicide, or given some indication that it had been in their minds'. Clouston concluded that while the suicide risk in melancholia was statistically very high, his experience told him that 'the actual risk of suicide being seriously attempted or accomplished is much less than those figures seem to show'. ${ }^{82}$ Nevertheless, the recording practices put in place by Clouston at Morningside contributed to the widely accepted view of a close relationship between melancholia and suicidal tendencies, with consequences for the admission, diagnosis, and care of melancholics in the Victorian period.

\section{CONCLUSION}

The developments mapped in this and the previous chapter have continued to shape perceptions of mood disorders into the twenty-first century, where emotional pain and depression are perceived as closely linked to suicidal thoughts and actions. Closely related to the emergence of suicidality as a category separate from suicide has been the growing focus of psychiatric attention in the late nineteenth and throughout the twentieth century upon 'self-injurious' behaviour. Late Victorian medical psychologists increasingly used the term 'self-mutilation' to describe a 
range of what they perceived to be non-suicidal acts, such as amputations and castrations; more commonly, however, medical discussion of 'self-mutilating' behaviour referred to 'minor self-mutilations' such as 'skin-picking' and 'hair-plucking'. ${ }^{83}$ In present psychiatry, 'non-suicidal self-injury' has become a firmly cemented medical concept ${ }^{84}$; however, the parameters and definitions of what distinguishes suicidal from nonsuicidal self-injury have shifted over time as these categories have been reconceptualised in the context of contemporaneous cultural tropes about group and individual behaviours. The history of these psychiatric models of behaviour is beyond the scope of this book, and have been considered elsewhere. ${ }^{85}$ However, it is significant to note the varying and multiple medical meanings of different kinds of 'self-injurious' behaviours in the nineteenth century. In sum, 'suicidal' was produced as a multivalent and shifting concept, one which was at the same time remarkably consistent in medico-psychological literature and in administrative and clinical practice for a time. Despite the fact that Victorian physicians themselves acknowledged the ambiguity of the concept and the problems attached to its use in the production of asylum statistics, they nevertheless continued to rely upon this category as a significant diagnostic criterion in the definition of melancholia, and as a useful tool in the determination of a patient's state of mind.

This chapter has traced the relationship between asylum statistics, diagnostic records, and published material to show how melancholia was constituted, modified, reified, and applied as a diagnosis in late Victorian medicine. Melancholia did not exist as a coherent disease entity with clearly distinguished symptoms prior to the practices and the language which sought to identify and classify it. If we want to say something about how psychiatric diagnoses were produced in the nineteenth century (and beyond), we must address the relationship between asylum case notes, which were often messy and inconsistent, and published material where neat psychiatric categories were described together with evidence drawn from such case notes, here presented as clear and organised narratives. We must pay attention to how such material was disseminated and discussed, and how the categories present in published literature made their way back to the asylum recording books. We need also to look at the relationship between the science of medicine and the science of statistics, as well as that between statistics, legal reforms, and subsequent changes to practice, and, finally, we must also consider to what extent different practices transformed the nature of the knowledge that emerged from 
the asylum casebook and was translated into textbooks and journals. Late Victorian melancholia was constituted as a disorder of emotion chiefly characterised by 'depression', 'mental pain', 'suicidal propensities', and 'religious delusions'. In the last quarter of the nineteenth century the diagnosis was remarkably coherent and precise; however a comparison between published literature and asylum records illustrates the conflicts that arise and, consequently, the negotiations that must take place when medicine seeks to label and classify the complexities of human life.

\section{Notes}

1. Thomas S. Clouston, Clinical Lectures on Mental Diseases (London: J. \& A. Churchill, 1883), 35.

2. Royal Edinburgh Asylum, Male Casebooks, 1874-1875, Lothian Health Services Archives, Edinburgh University Library, Ref: LHB 7/51/25.

3. Joseph J. Brown, "Case of Determined Suicidal Melancholia," Edinburgh Medical Journal 20 (1874): 402.

4. Thomas S. Clouston, "Report of the Physician-Superintendent for the Year 1874," Annual Report of the Royal Edinburgh Asylum for the Insane, Morningside, Royal Edinburgh Asylum (1875), 15.

5. Union Chargeability: A Bill to Provide for Better Distribution of Charge for Relief of Poor in Unions, House of Commons, 1865, Vol. IV.607.

6. Clouston, "Report: 1874," 13.

7. In England and Wales, two physicians were required for private patients, one for paupers.

8. See e.g. Andrew Scull, ed., Madhouses, Mad-Doctors, and Madmen: The Social History of Psychiatry in the Victorian Era (Philadelphia: University of Pennsylvania Press, 1981), and The Most Solitary of Afflictions: Madness and Society in Britain 1700-1900 (New Haven: Yale University Press, 1993); Anne Digby, Madness, Morality, and Medicine: A Study of the York Retreat, 1796-1914 (Cambridge: Cambridge University Press, 1985); Bill Forsythe and Joseph Melling, The Politics of Madness: The State, Insanity, and Society in England, 1845-1914 (London: Routledge, 2006); Charlotte McKenzie, Psychiatry for the Rich: A History of Ticehurst Private Asylum, 1792-1917 (London: Routledge, 1992); David Wright, Mental Disability in Victorian England: The Earlswood Asylum 1847-1901 (Oxford: Clarendon Press, 2001); Nancy Tomes, A Generous Confidence: Thomas Story Kirkbride and the Art of Asylum Keeping, 1840-1883 (Cambridge: Cambridge University Press, 1984).

9. Scull, "The Social History of Psychiatry in the Victorian Era," in Madhouses, Mad-Doctors, and Madmen, 12-13. 
10. Andrew Scull, The Insanity of Place, the Place of Insanity: Essays on the History of Psychiatry (London: Routledge, 2006), 110.

11. Ann Goldberg, Sex, Religion and the Making of Modern Madness: The Eberbach Asylum and German Society, 1815-1849 (Oxford: Oxford University Press, 1999), 5.

12. Forsythe and Melling, The Politics of Madness.

13. Akihito Suzuki, "Framing Psychiatric Subjectivity: Doctor, Patient and Record-Keeping at Bethlem in the Nineteenth Century," in Insanity, Institutions and Society, 1800-1914: A Social History of Madness in Comparative Perspective, eds. Joseph Melling and Bill Forsythe (London: Routledge, 1999).

14. Anne Shepherd and David Wright, "Madness, Suicide, and the Victorian Asylum: Attempted Self-Murder in the Age of Non-Restraint," Medical History 46 (2002): 175-196.

15. Goldberg, Making of Modern Madness, 5 .

16. Jonathan Andrews, Asa Briggs, Roy Porter, Penny Tucker, and Keir Waddington, The History of Bethlem (London and New York: Routledge, 1997); Alan Beveridge, "Madness in Victorian Edinburgh: A Study of Patients Admitted to the Royal Edinburgh Asylum under Thomas Clouston, 1873-1908: Part I \& II," History of Psychiatry 6 (1995): 2154, 133-156; Sarah Chaney, "Suicide, Mental Illness and the Asylum: The Case of Bethlem Royal Hospital, 1845-1875' (MA diss., University College London, 2009); McKenzie, Psychiatry for the Rich; Trevor Turner, A Diagnostic Analysis of the Casebooks of Ticehurst House Asylum, 1845-1890 (Cambridge: Cambridge University Press, 1992).

17. Scottish Lunacy Commission, Report by Her Majesty's Commissioners Appointed to Inquire into the State of Lunatic Asylums in Scotland, Edinburgh, printed for Her Majesty's stationary office by Thomas Constable, 1857.

18. Lunacy Act (Scotland), 1857. Its first chief medical commissioner was the reputable Scottish alienist W.A.F. Browne, father of James CrichtonBrowne.

19. Thomas S. Clouston, "Report of the Physician-Superintendent for the Year 1876," Annual Report of the Royal Edinburgh Asylum for the Insane, Morningside, Royal Edinburgh Asylum (1877), 10-11.

20. David Kennedy Henderson, The Evolution of Psychiatry in Scotland (Edinburgh: E. \& S. Livingstone, 1964), 93-93; Jonathan Andrews and Iain Smith, "The Evolution of Psychiatry in Glasgow during the Nineteenth and Early Twentieth Centuries," in 150 Years of British Psychiatry: Vol. 2: The Aftermath, eds. German E. Berrios and Hugh Freeman (London: Athlone Press, 1996), 313; Alan Beveridge, "Madness in Victorian Edinburgh: A Study of Patients Admitted to the Royal 
Edinburgh Asylum under Thomas Clouston, 1873-1908: Part I," History of Psychiatry 6 (1995): 23-24.

21. (Author unknown) "Sir Thomas Smith Clouston: Obituary," BMJ (April 24, 1915): 744-746. That Clouston's obituary spanned almost three full pages in the $B M J$ (and was accompanied by a shorter piece by his protégé and successor, George Robertson) testifies to the prominent position he had achieved in the British medical community by the time of his death. Despite this, little has been written about the man himself by historians; however, a brief account can be found in Allan Beveridge, "Thomas Clouston and the Edinburgh School of Psychiatry," in 150 Years of British Psychiatry, 1841-1991, eds. German E. Berrios and Hugh Freeman (London: Gaskell, 1991).

22. "Thomas Laycock: Obituary," 448.

23. Thomas S. Clouston, "The Study of Mental Disease, being the Introductory Lecture Delivered in the University of Edinburgh, on the Institution of the Lectureship on Mental Diseases, May 1879," Edinburgh Medical Journal 25 (1879): 3.

24. George M. Robertson, 'The Hospitalisation of the Scottish Asylum System', The Presidential Address Delivered at the Annual Meeting Held in the Hall of the Royal College of Physicians, Edinburgh, on Wednesday, July 19, 1922 (London: Adlard \& Son and West Newman, 1922).

25. David Skae, "A Rational and Practical Classification of Insanity," Journal of Mental Science 47 (1863): 311.

26. For a different kind of analysis of Clouston's reports than the one undertaken here, see Beveridge, "Madness in Victorian Edinburgh, Part I \& II," 21-54, 133-156.

27. Thomas S. Clouston, "Report of the Physician-Superintendent for the Year 1873," Annual Report of the Royal Edinburgh Asylum for the Insane, Morningside, Royal Edinburgh Asylum (1874), nl4-15.

28. Clouston, "Report: 1874," 15.

29. Beveridge, "Madness in Victorian Edinburgh, Part II," 135.

30. Clouston, "Report: 1874," 40.

31. Clouston, Clinical Lectures, 33-34. Emphasis in original. See also Thomas S. Clouston, "The Relationship of Bodily and Mental Pain," Weekly Medical Review 14 (1886): 600-609.

32. Clouston, Clinical Lectures, 35.

33. Clouston, Clinical Lectures, 37.

34. Clouston, Clinical Lectures, 38.

35. Clouston, Clinical Lectures, 38-40.

36. Clouston, Clinical Lectures, 40-41.

37. Clouston, Clinical Lectures, 64-79. Clouston did, however, also note the occasional 'untypical' case in his published material. See Thomas S. Clouston, "A Peculiar Case of Melancholia, with Cancerous Tumour 
of the Middle Lobe of Brain, Disease of Kidneys, Liver, Pylorus, \&c.," Journal of Mental Science 23, No. 104 (1878): 565-571.

38. Clouston, Clinical Lectures, 90-91.

39. Thomas S. Clouston, "On Mental Nursing," reprinted from The Morningside Mirror, from three lectures delivered to asylum staff on 24 Nov 1887, Royal Edinburgh Asylum Staff Publications, Lothian Health Services Archives, University of Edinburgh, 2. The Morningside Mirror was the asylum's own publication, born after a printing press was installed at Morningside in 1845 .

40. Clouston, Clinical Lectures, 107.

41. See Chapter 5.

42. Clouston, Clinical Lectures, 112.

43. John Harley Warner, "The Uses of Patient Records by Historians: Patterns, Possibilities, and Perplexities," Health and History 1, No. 2/3 (1999): 109.

44. Medical Certificates and Reception Order for Isabella Kay, admitted 31 July 1893, Lothian Health Services Archives, University of Edinburgh, Ref: LHB7/52/724.

45. Royal Edinburgh Asylum, Female Casebooks, June 1893-June 1894, Lothian Health Services Archives, University of Edinburgh, Ref: $\mathrm{LHB} 7 / 51 / 60$.

46. Royal Edinburgh Asylum, Female Casebooks, August 1876-April 1878, Lothian Health Services Archives, University of Edinburgh, Ref: LHB7/51/31.

47. Royal Edinburgh Asylum, Male Casebooks, October 1876-April 1878, Lothian Health Services Archives, University of Edinburgh, Ref: $\mathrm{LHB} 7 / 51 / 30$.

48. Royal Edinburgh Asylum, Female Casebooks, June 1893-June 1894, Lothian Health Services Archives, University of Edinburgh, Ref: LHB7/51/60.

49. Royal Edinburgh Asylum, Male Casebooks, July 1893-August 1894, Lothian Health Services Archives, University of Edinburgh, Ref: LHB7/51/61.

50. Female Casebook (Edinburgh), June 1893-June 1894.

51. Male Casebook (Edinburgh), July 1893-August 1894.

52. Royal Edinburgh Asylum, Female Casebooks, December 1897-December 1898, Lothian Health Services Archives, University of Edinburgh, Ref: LHB7/51/72.

53. David Walker and Anita O'Connell, "Introduction," in Depression and Melancholy, 1660-1800, Vol 1: General Introduction \& Religious Writings, eds. Leigh Wetherall Dickson, Allan Ingram, David Walker, and Anita O'Connell (London: Pickering \& Chatto, 2012).

54. Male Casebook (Edinburgh), October 1876-April 1878. 
55. Female Casebook (Edinburgh), August 1876-April 1878.

56. Royal Edinburgh Asylum, Female Casebooks, April 1887-July 1888, Lothian Health Services Archives, University of Edinburgh, Ref: LHB7/51/48.

57. Royal Edinburgh Asylum, Male Casebooks, November 1887-March 1889, Lothian Health Services Archives, University of Edinburgh, Ref: $\mathrm{LHB} 7 / 51 / 49$.

58. Male Casebook (Edinburgh), October 1876-April 1878.

59. Female Casebook (Edinburgh), August 1876-April 1878.

60. Brookwood Female Casebook 1878-1880 Ref: 3043/5/9/2/11.

61. Female Casebook (Brookwood) 1878-1880.

62. Brookwood Male Casebook 1869-1872 Ref: 3043/5/9/1/2.

63. Thomas S. Clouston, "Physician-Superintendent's Annual Report for the Year 1887," Annual Report of the Royal Edinburgh Asylum for the Insane, Morningside, Royal Edinburgh Asylum (1888), 14.

64. Clouston, "Report: 1887," 41.

65. Female Casebook (Edinburgh), April 1887-July 1888.

66. Brown, "Suicidal Melancholia"; Royal Edinburgh Asylum, Male Casebooks, January 1874-April 1875, Lothian Health Services Archives, University of Edinburgh, Ref: LHB7/51/26.

67. Female Casebook (Edinburgh), August 1876-April 1878.

68. Female Casebook (Edinburgh), August 1876-April 1878; Male Casebook (Edinburgh), October 1876-April 1878; Female Casebook (Edinburgh), April 1887-July 1888.

69. Male Casebook (Edinburgh), November 1887-March 1889; Female Casebook (Edinburgh), June 1893-June 1894.

70. Male Casebook (Edinburgh), July 1893-August 1894.

71. Female Casebook (Edinburgh), December 1897-December 1898.

72. Female Casebook (Edinburgh), December 1897-December 1898; Female Casebook (Edinburgh), April 1887-July 1888; Male Casebook (Edinburgh), November 1887-March 1889.

73. Henry Maudsley, The Pathology of Mind, 3rd ed. (London: Macmillan, 1879), 384.

74. Brookwood Male Casebook 1869-1872 Ref: 3043/5/9/1/2.

75. Brookwood Female Casebooks 1868-1871 Ref: 3043/5/9/2/3.

76. Brookwood Male Casebook 1869-1872 Ref: 3043/5/9/1/2.

77. Pauper relief in Scotland was subject to the Poor Law (Scotland) Act of 1845, which had created a system similar to the English one implemented in 1834. For a more comprehensive discussion of the relationship between the Scottish pauper and lunacy laws, see Margaret Sorbie Thompson, "The Mad, the Bad, and the Sad: Psychiatric Care in the Royal Edinburgh Asylum (Morningside), 1813-1894" (PhD diss., Boston University, 1984), 18-31. 
78. Female Casebook (Edinburgh), April 1887-July 1888.

79. Male Casebook (Edinburgh), November 1887-March 1889.

80. Clouston, Clinical Lectures, 107.

81. Thomas S. Clouston, "Report of the Physician-Superintendent for the Year 1879," Annual Report of the Royal Edinburgh Asylum for the Insane, Morningside, Royal Edinburgh Asylum (1880), 18-19.

82. Clouston, Clinical Lectures, 118.

83. Sarah Chaney, "Self-Control, Selfishness, and Mutilation: How Medical Is Self-Injury Anyway?" Medical History 55, No. 3 (2011): 377-380. See also Sarah Chaney, Psyche on the Skin: A History of Self-Harm (London: Reaktion Books), 2017.

84. See e.g. Diagnostic and Statistical Manual for Mental Disorders, Fifth Edition (DSM-5) (Washington, DC: The American Psychiatric Association, 2013), 803-805.

85. See Chaney, "Self-Control, Selfishness, and Mutilation," and Psyche on the Skin. For mid-twentieth-century psychiatric conceptions of 'attempted suicide', see Chris Millard, A History of Self-Harm in Britain: A Genealogy of Cutting and Overdosing (London: Palgrave Macmillan), 2015.

Open Access This chapter is licensed under the terms of the Creative Commons Attribution 4.0 International License (http://creativecommons.org/licenses/ by $/ 4.0 /)$, which permits use, sharing, adaptation, distribution and reproduction in any medium or format, as long as you give appropriate credit to the original author(s) and the source, provide a link to the Creative Commons license and indicate if changes were made.

The images or other third party material in this chapter are included in the chapter's Creative Commons license, unless indicated otherwise in a credit line to the material. If material is not included in the chapter's Creative Commons license and your intended use is not permitted by statutory regulation or exceeds the permitted use, you will need to obtain permission directly from the copyright holder.

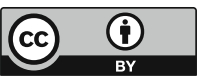

